\title{
Recomendaciones para la vacunación segura en niños con riesgo de padecer reacciones alérgicas a componentes vacunales
}

\author{
Recommendations for safe vaccination in children at the risk of \\ taking allergic reactions to vaccine components
}

\author{
Comité Nacional de Infectología y Comité Nacional de Alergia
}

\begin{abstract}
RESUMEN
Las vacunas son uno de los avances más importantes dela medicina como herramienta de salud pública para el control delas enfermedades inmunoprevenibles. Ocasionalmente, pueden producir reacciones adversas. Si un niño presenta alguna reacción con una vacuna, es probable que interrumpa su plan de inmunizaciones, con riesgos para él y para la comunidad. Esto jerarquiza la importancia de realizar el correcto diagnóstico de una posible alergia y definir la conducta apropiada.

Las reacciones alérgicas a vacunas pueden ser debidas al componente inmunogénico, a las proteínas residuales del proceso de fabricación y a los agentes antimicrobianos, estabilizantes, conservantes y cualquier otro elemento utilizado en el proceso de elaboración.

La vacunación debe ser una prioridad en toda la población, por lo cual este documento describe situaciones particulares de niños alérgicos para minimizar el riesgo frente a las inmunizaciones y lograr una vacunación segura.

Palabras clave: vacunas, reacciones adversas, alergia, hipersensibilidad al huevo, inmunización.
\end{abstract}

\section{ABSTRACT}

Vaccines are one of the most important advances in medicine as a public health tool for the control of immunopreventable diseases. Occasionally, adverse reactions may occur. If a child has a reaction to a vaccine, it is likely to disrupt his immunization schedule with risks to himself and the community. This establishes the importance of correctly diagnosing a possible allergy and defining appropriate behavior.

Correspondencia: Dra. Andrea Mariño: aimarino1966@yahoo. com.ar;

Dra. Ángela Gentile: angelagentile21@gmail. com;

Dr. Héctor Abate:

hjabate@gmail.com.

Financiamiento:

Ninguno.

Conflicto de intereses: Ninguno que declarar.

Recibido: 8-9-2017 Aceptado: 19-9-2017
Vaccination should be a priority in the entire child population, so this document describes particular situations of allergic children to minimize the risk of immunizations and achieve safe vaccination. Key words: vaccine, adverse reaction, allergy, egg allergy, immunization.

http:/ / dx.doi.org/10.5546/ aap.2018.S34

Cómo citar: Comité Nacional de Infectología, Comité Nacional de Alergia. Recomendaciones para la vacunación segura en niños con riesgo de padecer reacciones alérgicas a componentes vacunales. Arch Argent Pediatr 2018;116(Supl2):S34-S47.

\section{INTRODUCCIÓN}

Las vacunas representan uno de los avances más importantes de la medicina y salvan diariamente la vida de millones de niños alrededor del mundo. Son productos medicinales seguros y eficaces, diseñados para generar protección contra enfermedades infecciosas.

Ocasionalmente, pueden generar reacciones adversas. La mayoría de estas son leves e incluyen malestar, edema o enrojecimiento en el sitio de la inyección. Algunas vacunas pueden provocar fiebre, exantemas y dolor. Los efectos graves son excepcionales, como reacciones alérgicas sistémicas y síntomas neurológicos. ${ }^{1}$

Coordinación general: Dra. Ángela Gentile, ${ }^{a}$ Dr. Héctor Abate. ${ }^{a}$

Coordinadores: Dras. Ana Ceballos, ${ }^{a}$ Andrea Mariño. ${ }^{b}$

Autores: Dres. Andrea Mariño, ${ }^{a}$ María Paula Sarraquigne ${ }^{b}$ Gloria Bandin,${ }^{b}$

Karina López, ${ }^{b}$ María Eugenia Gervasoni, ${ }^{b}$ Claudio Parisi, ${ }^{b}$ Martín Bózzola, ${ }^{b}$

Raúl Boudet, ${ }^{b}$ Claudio Agüero, ${ }^{b}$ Alejandro Lozano, ${ }^{b}$ Ricardo Saranz, ${ }^{b}$ Victor Skrie, ${ }^{b}$

Ángela Gentile, ${ }^{a}$ Héctor Abate, ${ }^{a}$ Ana Ceballos, ${ }^{a}$ Miriam Calvari, ${ }^{a}$ Liliana Asis. ${ }^{a}$ 
Si bien los reportes de cualquier tipo de eventos supuestamente atribuibles a vacunación o inmunización (ESAVI) son voluntarios, la Administración Nacional de Medicamentos, Alimentos y Tecnología Médica (ANMAT), a través de los informes del Departamento de Farmacovigilancia, nuclea las cifras del país y las publica anualmente. ${ }^{2}$ Las cifras publicadas en los últimos 10 años se muestran en la Figura 1.

Con el objetivo de actualizar las recomendaciones de vacunas en situaciones particulares de niños alérgicos y evitar riesgos en los procesos de vacunación, el Comité Nacional de Alergia y el de Infectología trabajaron en conjunto, teniendo en cuenta la evidencia científica publicada en revistas indexadas.

\section{Reacciones alérgicas}

Según su extensión, las reacciones alérgicas por vacunas se clasifican en locales o sistémicas y, según el tiempo transcurrido, desde su aplicación hasta la aparición de los síntomas, en inmediatas o retardadas (Tabla 1). Este último criterio ayuda a distinguir las reacciones de tipo inmediato, mediado por inmunoglobulina $\mathrm{E}$ (IgE), potencialmente más graves, de las que no lo son. ${ }^{3}$

\section{Reacciones alérgicas a componentes vacunales}

Las reacciones alérgicas a vacunas pueden ser debidas al componente inmunogénico, a las proteínas residuales del proceso de fabricación y a los agentes antimicrobianos, estabilizantes, conservantes y cualquier otro elemento utilizado en el proceso de elaboración. ${ }^{4}$

En este documento, se presenta una tabla que incluye todas las formulaciones comercializadas en la actualidad en nuestro país, con sus respectivos componentes, que orientará sobre el reconocimiento de la conducta adecuada para la vacunación segura en niños alérgicos a componentes vacunales (véase el Anexo).

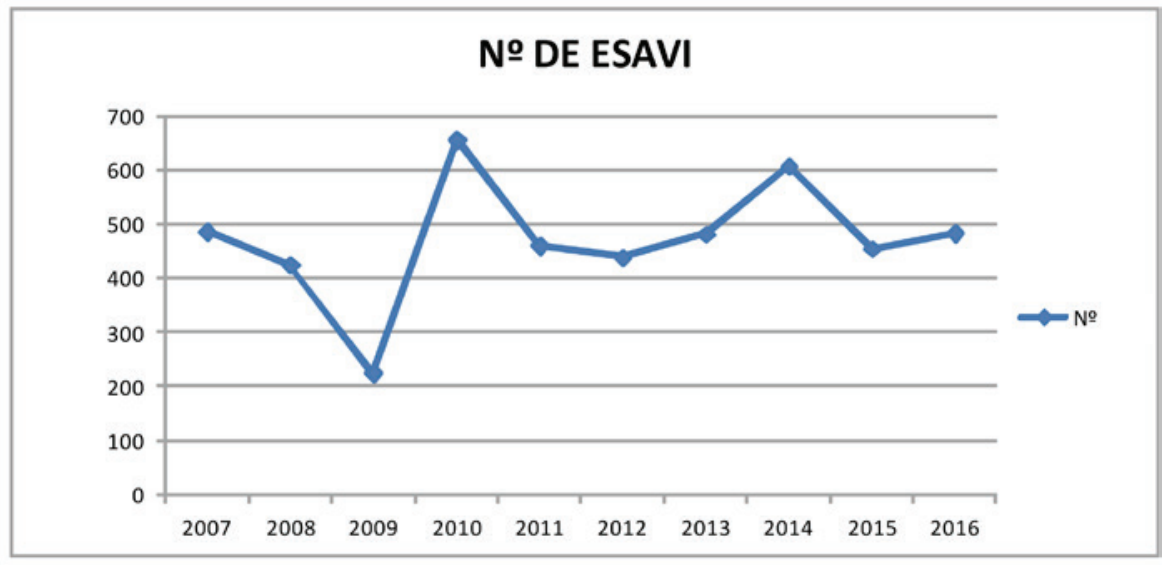

ESAVI: eventos supuestamente atribuibles a vacunación o inmunización.

Fuente: ANMAT. Departamento de Farmacovigilancia. Reportes anuales de 2007 a 2016.

TABLA 1. Tipo de reacción según gravedad

\begin{tabular}{|l|l|l|}
\hline \multicolumn{1}{|c|}{ Gravedad } & \multicolumn{1}{c|}{ Leve } & \multicolumn{1}{c|}{ Grave } \\
\hline $\begin{array}{l}\text { Tipo de reacción } \\
\begin{array}{l}\text { Local } \\
\text { Tipos I, II, III, IV de Gell y }\end{array}\end{array}$ & $\begin{array}{l}\text { Limitado a la periferia de la } \\
\text { reacción }(<6 \mathrm{~cm})\end{array}$ & $\begin{array}{l}\text { Referido al sitio de la } \\
\text { aplicación, pero extendido } \\
(>6 \mathrm{~cm})\end{array}$ \\
\hline $\begin{array}{l}\text { Sistémico } \\
\text { Tipo I de Gell y Coombs }\end{array}$ & $\begin{array}{l}\text { Lesiones cutáneas } \\
\text { generalizadas: urticaria }\end{array}$ & $\begin{array}{l}\text { Lesiones cutáneas } \\
\text { generalizadas a las que se } \\
\text { agregan manifestaciones } \\
\text { respiratorias y/o } \\
\text { cardiovasculares: anafilaxia }\end{array}$ \\
\hline
\end{tabular}




\section{A) Reacciones alérgicas hacia el componente inmunogénico de las vacunas}

Estas reacciones son excepcionales; su prevalencia oscila entre 0,5 y 1 en 100000 dosis. Se han descrito asociadas a vacunas contra difteria, pertussis y tétanos entera (DPT) y acelular (DPTa), y conllevan la contraindicación absoluta para nuevas dosis de la vacuna implicada. ${ }^{4,5}$

\section{B) Reacciones alérgicas a otros componentes de las vacunas}

1. Proteínas residuales en medios de cultivo

1.1. Reacciones alérgicas por proteínas residuales de huevo

Las más frecuentes son las relacionadas con las proteínas del huevo. La prevalencia estimada de la alergia a este alimento en niños pequeños oscila entre $0,5 \%$ y $7 \% .{ }^{6,7}$ La cantidad de proteínas de huevo presentes en una vacuna depende del proceso de fabricación, y pueden distinguirse los dos tipos siguientes:

\subsubsection{Vacunas preparadas a partir de fibroblastos de embrión de pollo}

Las vacunas contra la rabia y la triple vírica son preparadas en cultivos de fibroblastos de embrión de pollo. El producto final contiene trazas de proteínas residuales relacionadas con el huevo.

En la actualidad, se acepta que la vacuna triple vírica se puede administrar de manera segura a niños con alergia demostrada al huevo. Solo aquellos niños que hayan padecido reacciones graves IgE mediadas por huevo deberán aplicársela en un ambiente con capacidad de tratar eficazmente una reacción anafiláctica. ${ }^{8,9}$

\subsubsection{Vacunas preparadas en huevos embrionados de pollo}

Otras vacunas, como aquellas contra la gripe y la fiebre amarilla, se obtienen a partir de huevos embrionados de pollo. Los virus se cultivan en el líquido alantoideo embrionario del pollo, por lo que la cantidad de dicha proteína puede variar entre 0,2 y $42 \mu \mathrm{g} / \mathrm{ml}$.

En diversos estudios, se ha demostrado que la vacunación parece ser inocua en pacientes con alergia a proteínas de huevo cuando la cantidad de ovoalbúmina no excede $1,2 \mu \mathrm{g} / \mathrm{ml}$ (equivalente a $0,6 \mu \mathrm{g} /$ dosis). ${ }^{5,9}$

En pacientes con alergia a proteínas de huevo, deben seleccionarse formulaciones con concentraciones de ovoalbúmina menores de esa cantidad, como la que se incluye actualmente en el Programa Ampliado de Inmunizaciones (PAI) de Argentina (véase el Anexo), y deben aplicarse en ambientes que cuenten con recursos para tratar episodios anafilácticos. ${ }^{9}$

\subsection{Reacciones alérgicas por proteínas residuales de levadura}

Las actuales vacunas recombinantes contra la hepatitis B y el virus del papiloma humano vigente en el PAI se producen en cultivos celulares de Saccharomyces cerevisiae, que pueden contener cantidades residuales de proteínas de levadura. Se han descrito reacciones de hipersensibilidad inmediata tras la vacunación contra la hepatitis B con muy baja frecuencia ( 1 en 100000 dosis).5,10 Ante esta situación, se recomienda la interconsulta con el especialista en alergia.

\subsection{Reacciones alérgicas por proteínas residuales de leche de vaca}

Las vacunas que contienen combinación de las bacterias de difteria y tétanos están preparadas en un medio de cultivo proveniente de proteínas de leche de vaca, que contiene ácido casamino, derivado de la caseína hidrolizada, que se emplea como nutriente celular. Los niños con alergia a la proteína de la leche de vaca (APLV) mediada por IgE tienen riesgo de anafilaxia con su aplicación. ${ }^{11-15} \mathrm{Si}$ bien no existen datos de prevalencia en Argentina, se calcula que, a nivel mundial, la APLV oscila entre el $2 \%$ y el $7,5 \%$, mientras que la hipersensibilidad inmediata se estima en $1-2 \%$ en niños pequeños. ${ }^{14,15}$ Se debe consultar al alergólogo para una inmunización segura en niños con anafilaxia por APLV.

\section{Aditivos}

\subsection{Antibióticos}

Los aminoglucósidos (gentamicina, kanamicina), polimixina, clortetracicilina y la neomicina, que es el más ampliamente utilizado, se añaden a las vacunas para evitar la contaminación bacteriana durante el proceso de fabricación. ${ }^{13}$ Ciertas vacunas, como la triple vírica, la antivaricela, la intramuscular frente a la polio y las combinadas, como las pentavalentes y hexavalentes, la mayoría de las vacunas antigripales, la antirrábica y alguna de las vacunas frente a la hepatitis A (véase el Anexo), contienen pequeñas cantidades de neomicina. Las alergias de contacto a este antibiótico, añadido durante el proceso de fabricación de estas vacunas, no constituyen una contraindicación 
para la inmunización por representar una respuesta inmune retardada. Las reacciones anafilácticas, IgE mediadas, a neomicina o a otros aminoglucósidos (por su posibilidad de reacción cruzada) requerirán de una administración estrictamente supervisada., 5

\subsection{Preservativos}

Derivados del mercurio

El tiomersal o timerosal es un compuesto orgánico mercurial utilizado para inhibir el crecimiento bacteriano, que, en bajas concentraciones, no produce efectos adversos. Puede generar reacciones retardadas que no tienen implicancia a nivel clínico y no contraindican las dosis posteriores. ${ }^{5,13}$

\subsection{Estabilizantes}

\section{Lactoalbúmina}

La vacuna contra el virus de la polio por vía oral puede contener lactoalbúmina. Los niños con APLV mediada por IgE tienen riesgo de anafilaxia con su administración. ${ }^{14,15}$ El pediatra deberá interconsultar con el alergólogo para vacunar sin riesgo a estos pacientes.

\section{Gelatina}

La gelatina, en cantidades que oscilan entre microgramos y miligramos, se utiliza como estabilizante en vacunas de virus atenuados, como la triple vírica o la vacuna de la varicela. Raramente, puede ocasionar reacciones alérgicas IgE mediadas. Los niños con riesgo de padecerla deben vacunarse en ambientes controlados. ${ }^{13,16}$

\subsection{Adyuvantes}

\section{Hidróxido de aluminio}

Este adyuvante, debido a una reacción de hipersensibilidad retardada, puede producir nódulos palpables persistentes en el sitio de la colocación. Esta situación no contraindica nuevas aplicaciones. ${ }^{17}$ Es recomendable, en estos pacientes, administrar la vacuna por vía intramuscular profunda para prevenir la formación de granulomas. ${ }^{13,17}$

\section{Sistemas de adyuvantes}

Es una combinación de adyuvantes dirigida a mejorar y modular la respuesta inmune a los antígenos. No hay suficiente evidencia que ligue el uso de vacunas con adyuvantes al desarrollo de enfermedad autoinmune, tanto para el MF59, utilizado en la vacuna contra la influenza, como en el ASO4, empleado en las vacunas contra el virus del papiloma humano bivalente y la hepatitis B, por lo cual su aplicación sigue siendo recomendable. ${ }^{18}$

\subsection{Residuos de inactivación Propiolactona}

La propiolactona es un agente inactivante que se utiliza en algunas vacunas antirrábicas. Se le atribuye un riesgo de anafilaxia de 1:10000 dosis aplicadas. ${ }^{5} \mathrm{Su}$ aplicación en niños que hayan realizado anafilaxia con dosis anteriores debe ser evaluada por el alergólogo infantil.

\section{Contaminante}

Látex

Las vacunas que son almacenadas en recipientes que contienen látex (frasco o jeringa prellenada) no deben ser administradas en pacientes con anafilaxia por esta proteína (véase el Anexo). Los niños con alergia confirmada al látex deben ser vacunados con precaución, en un ambiente libre de látex, y se deben evitar guantes, jeringuillas y otros materiales sanitarios que lo contengan. Deben aplicarse vacunas sin tapones de látex. Si no están disponibles, se debe tener la precaución de no atravesar con la aguja dicho tapón para obtener la dosis vacunal. Actualmente, la mayoría de los productos empleados son sintéticos (goma de butilo, goma de clorobutilo, goma de estireno, halobutilo). ${ }^{13,19}$

Los niños que presentan alergia de contacto con látex, no IgE mediada, pueden vacunarse en forma segura. ${ }^{19}$

\section{CONCLUSIONES}

La vacunación es la herramienta más importante de salud pública para el control de enfermedades inmunoprevenibles, por lo que debe priorizarse y, solo bajo circunstancias muy particulares, se considerará su contraindicación.

Las vacunas doble bacterianas son preparadas en un medio derivado de proteínas de leche de vaca y pueden contener nanocantidades de caseína, al igual que la poliovirus oral, que contiene alfalactoalbúmina. Ambas podrían ser responsables de anafilaxia en pacientes con APLV mediada por IgE. Se debe consultar al especialista en alergia para su aplicación en estos pacientes.

Las vacunas dobles y triples virales contienen cantidades mínimas de proteínas de huevo (de picogramos a nanogramos), por lo que su aplicación es segura en pacientes alérgicos al huevo, aun en aquellos con antecedentes de anafilaxia, que deberán recibirla en un centro con 
capacidad para tratar estas reacciones.

Las vacunas de la fiebre amarilla y antigripal contienen una mayor cantidad de proteínas de huevo (microgramos), por lo que, en niños con antecedentes de anafilaxia a él, su aplicación debe realizarse bajo control del médico alergólogo o personal entrenado en el tratamiento de reacciones anafilácticas.

Las recomendaciones actuales para la vacunación segura de niños con alergia mediada por IgE son las siguientes:

$\checkmark$ El médico especialista que ha diagnosticado

la alergia debe informar a los padres de su afección y dejar constancia en la libreta sanitaria.

$\checkmark$ Las personas identificadas deben vacunarse en centros que cuenten con infraestructura acorde a la potencial situación de emergencia (medicación específica, acceso a unidades de cuidados intensivos o soporte respiratorio).

$\checkmark$ Una vez aplicada la vacuna, deberá controlarse al niño por un período de 30 a 120 minutos, según la indicación del alergólogo.

$\checkmark$ En el caso de presentar un cuadro compatible con anafilaxia, deberá seguirse el protocolo correspondiente y reportar la reacción adversa.

$\checkmark$ Si presentara reacción anafiláctica moderada o grave, se hospitalizará al paciente por $24 \mathrm{~h}$, por la posibilidad de realizar una reacción bifásica. ${ }^{20}$

En líneas generales, en niños con diagnóstico de alergia a algún componente de las vacunas, con riesgo de anafilaxia, el pediatra deberá interconsultar con el especialista en alergología infantil para definir una vacunación segura.

Es importante no permitir que un niño quede sin vacunar por desconocimiento o miedo, ya que se expone a él, a su familia y a la población general a riesgos mayores.

\section{REFERENCIAS}

1. Kelso JM, Greenhawt MJ, Li JT, et al. Adverse reactions to vaccines practice parameter 2012 update. J Allergy Clin Immunol 2012;130(1):25-43.

2. ANMAT. Departamento de Farmacovigilancia. Informes de gestión anuales delSNFG. Buenos Aires: Ministerio deSalud. [Acceso: 6 de octubre de 2017]. Disponible en: http: / / www. anmat.gov.ar/farmacovigilancia/informesanuales.asp.

3. Wood RA. Allergic reactions to vaccines. Pediatr Allergy Immunol 2013;24(6):521-6.

4. Roush SW1, Murphy TV. Historical comparisons of morbidity and mortality for vaccine-preventable diseases in the United States. JAMA 2007; 298(18):2155-63.

5. Fernández Cuesta L M, González Rodríguez F, Huerta González I, et al. Reacciones alérgicas y componentes de las vacunas. En Vacunación del niño alérgico a los componentes de las vacunas. Asturias: Programa de Vacunaciones de Asturias. 2011:5-6. [Acceso: 6 de octubre de 2017]. Disponible en: https://www. asturias.es / Astursalud / Ficheros / AS_Salud\%20Publica / As_Vigilancia/Vacunas / Gu\% C3\% ADa $\% 20 \mathrm{de} \% 20$ vacunacion $\% 20 \mathrm{del} \% 20 \mathrm{ni} \% \mathrm{C} 3 \% \mathrm{~B} 1 \mathrm{o} \% 20$ alergico_dic2011. pdf.

6. Rüggeberg JU, Gold MS, Bayas JM, et al. Anaphylaxis: Case definition and guidelines for data collection, analysis, and presentation of immunization safety data. Vaccine 2007;25(31):5675-84.

7. Ronna R J, Keil T, Summers C, et al. The prevalence of food allergy: a meta-analysis. J Allergy Clin Immunol 2007;120(3):638-46.

8. Fina Avilés F, Campins Martí M, Martínez Gómez X, et al. Vacuna triple vírica y alergia al huevo. Experiencia en una unidad de vacunación hospitalaria. An Pediatr (Barc) 2007;67(4):362-7.

9. Greenhawt MJ, Spergel JM, Rank MA, et al. Safe administration of the seasonal trivalent influenza vaccine to children with severe egg allergy. Ann Allergy Asthma Immunol 2012;109(6):426-30.

10. DiMiceli L, Pool V, Kelso JM, et al. Vaccination of yeast sensitive individuals: review of safety data in the US vaccine adverse event reporting system (VAERS). Vaccine 2006;24(6):703-7.

11. Chung EH. Vaccine allergies. Clin Exp Vaccine Res 2014;3(1):50-7.

12. Kattan JD, Konstantinou GN, Cox AL, et al. Anaphylaxis to diphtheria, tetanus, and pertussis vaccines among children with cow's milk allergy. J Allergy Clin Immunol 2011;128(1):215-8.

13. Echeverría Zudaire L, Ortigosa del Castillo L, Alonso Lebreo E, et al. Documento de consenso sobre la actitud ante un niño con una reacción alérgica tras la vacunación o alergia a componentes vacunales. An Pediatr (Barc) 2015;83(1):63.e1-10.

14. Programa Nacional de Control de Enfermedades Inmunoprevenibles. Recomendaciones para la vacunación deniños con antecedentes de alergia a las proteínas de origen bovino / porcino, APOV, APOP (alergia a las proteínas de leche de vaca, APLV). Ministerio de Salud de la Nación. [Acceso: 6 deoctubre de 2017]. Disponibleen: http:/ / www. pediatriarosario.org.ar/download/voletindescargas / Recomendaciones \%20alergia\%20\%20APLV\%20pdf.pdf.

15. ParisiCA,SmaldiniPL, GervasoniME, etal.Hypersensitivity reactions to the Sabin vaccine in children with cow's milk allergy. Clinical Exp Allergy 2013;43(2):249-54.

16. Sakaguchi $M$, Inouye $S$. IgE sensitization to gelatin: the probable role of gelatin-containing diphtheriatetanus-acellular pertussis (DTaP) vaccines. Vaccine 2000;18(19):2055-8.

17. Bergfors E, Trollfors B. Sixty-four children with persistent itching nodules and contact allergy to aluminium after vaccination with aluminium-adsorbed vaccines-prognosis and outcome after booster vaccination. Eur J Pediatr 2013;172(2):171-7.

18. Vera-Lastra O, Medina G, Cruz Domínguez MdelP, et al. Autoimmune/inflammatory syndrome induced by adjuvants (Shoenfeld's syndrome): clinical and immunological spectrum. Expert Rev Clin Immunol 2013;9(4):361-73.

19. Caubet JC, Rudzeviciene O, Gomes E, et al. Managing a child with possible allergy to vaccine. Pediatr Allergy Immunol 2014;25(4):394-403.

20. Programa Nacional de Control de Enfermedades Inmunoprevenibles. Manual de VacunaciónSegura. Buenos Aires: Ministerio de Salud; 2012. [Acceso: 6 de octubre de 2017]. http://www.msal.gob.ar/images/stories/ epidemiologia/inmunizaciones / manual-vacunacionsegura-esavi.pdf. 
ANEXO

Componentes vacunales según tipo de vacuna

\begin{tabular}{|c|c|c|c|c|c|c|}
\hline 气̊ำ & 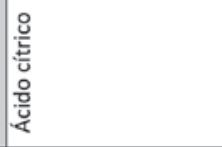 & & & & & \\
\hline 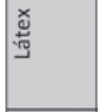 & & in & 证 & & & \\
\hline 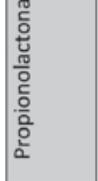 & & & & & iñ & \\
\hline 吾 & & 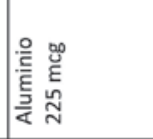 & 总 & & & \\
\hline 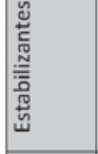 & & & & 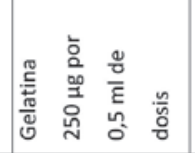 & & \\
\hline 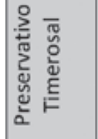 & & & & & 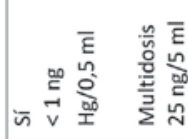 & 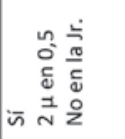 \\
\hline 尊 & & & & 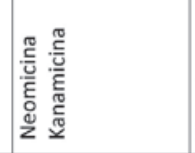 & 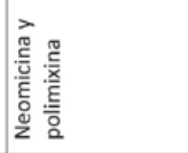 & 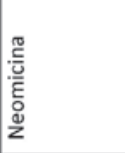 \\
\hline 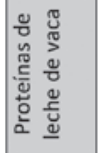 & & & & & & \\
\hline 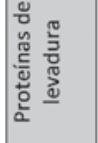 & & in & & & & \\
\hline 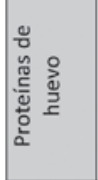 & & & & 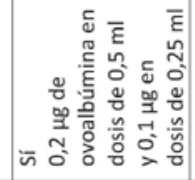 & & $\bar{n}$ \\
\hline 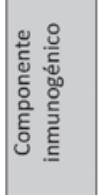 & 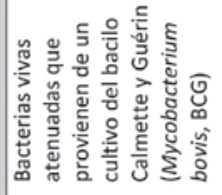 & 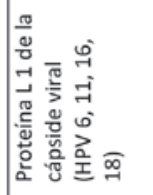 & 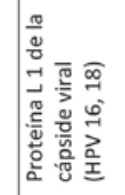 & 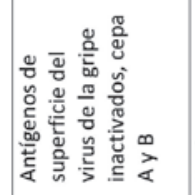 & 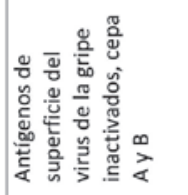 & 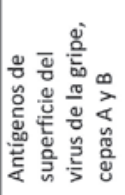 \\
\hline 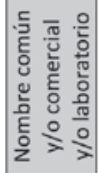 & 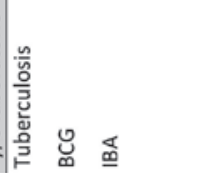 & 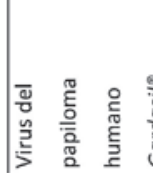 & 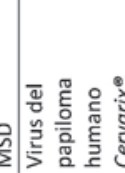 & 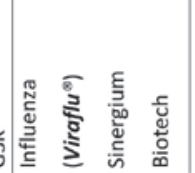 & 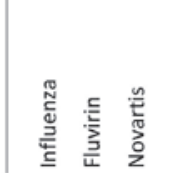 & 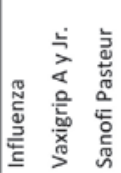 \\
\hline
\end{tabular}




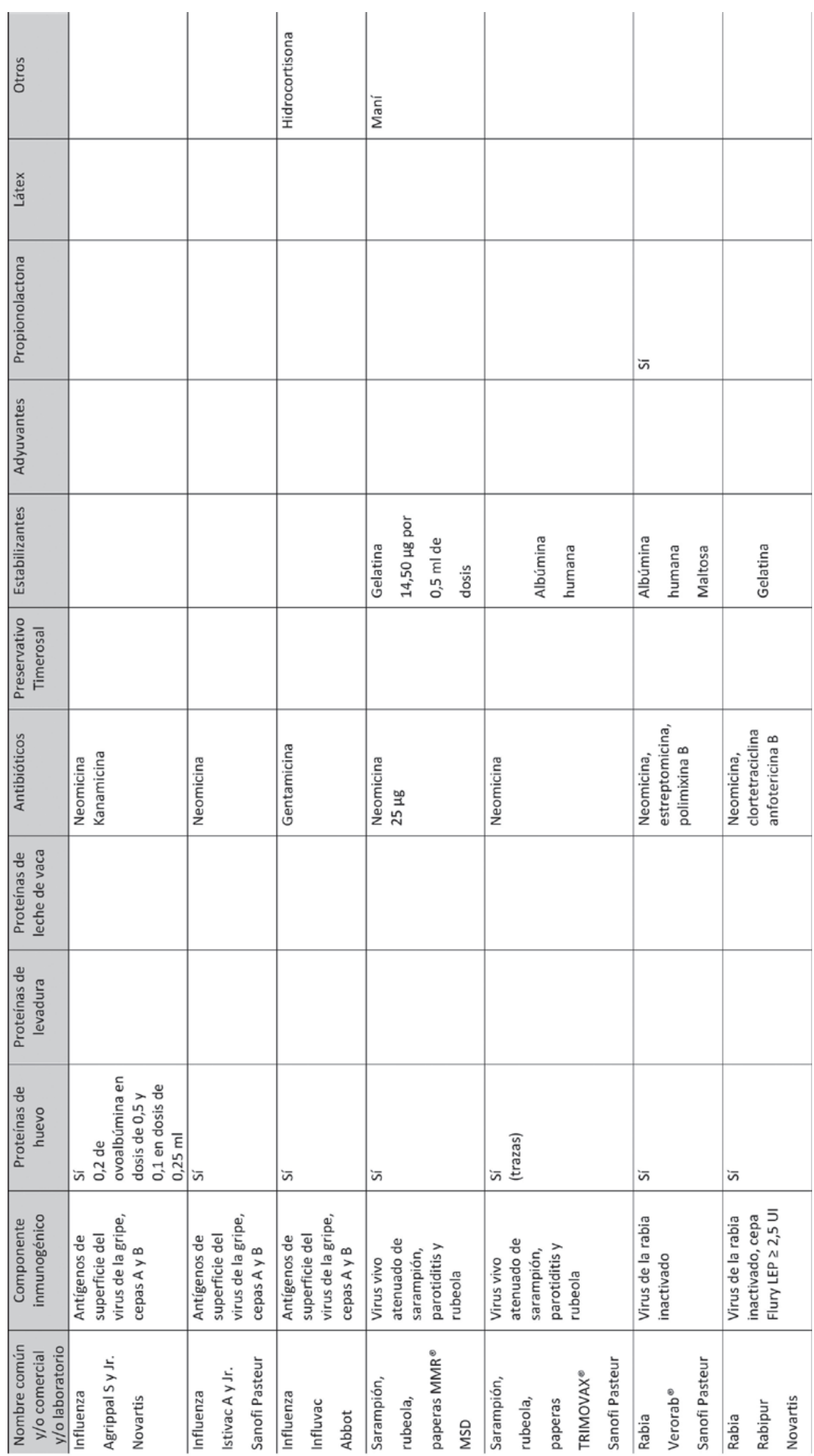




\begin{tabular}{|c|c|c|c|c|c|c|}
\hline o气 & 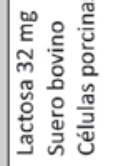 & 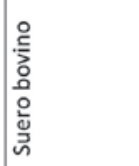 & & 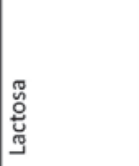 & 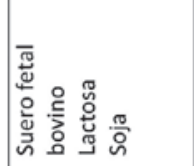 & \\
\hline 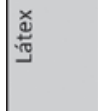 & & & & & 的兽 & \\
\hline 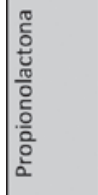 & & & & & & \\
\hline 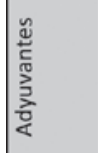 & & & & & & \\
\hline 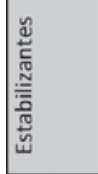 & 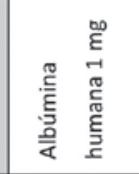 & 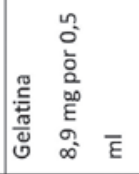 & 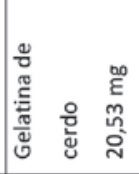 & & & \\
\hline 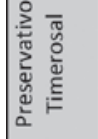 & & & & & & \\
\hline 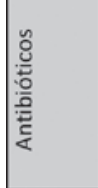 & 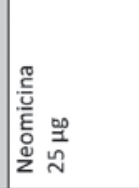 & 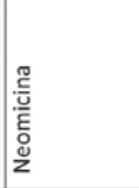 & 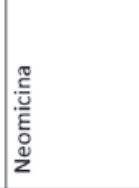 & & 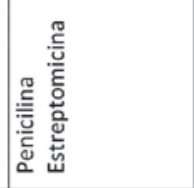 & \\
\hline 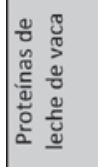 & 脑 & & & & & \\
\hline 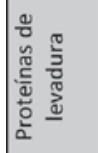 & & & & & & \\
\hline 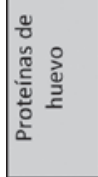 & & & & iñ & & \\
\hline 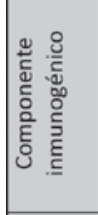 & 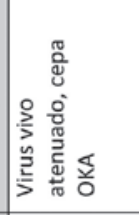 & 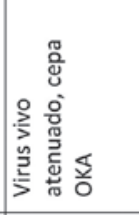 & 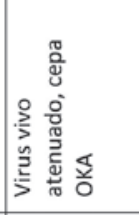 & 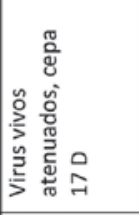 & 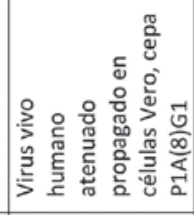 & 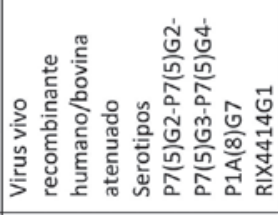 \\
\hline 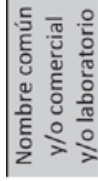 & 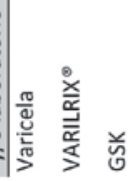 & 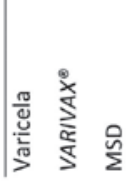 & 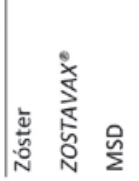 & 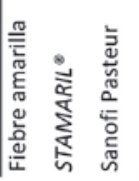 & 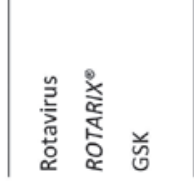 & 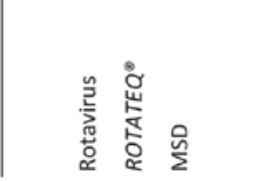 \\
\hline
\end{tabular}




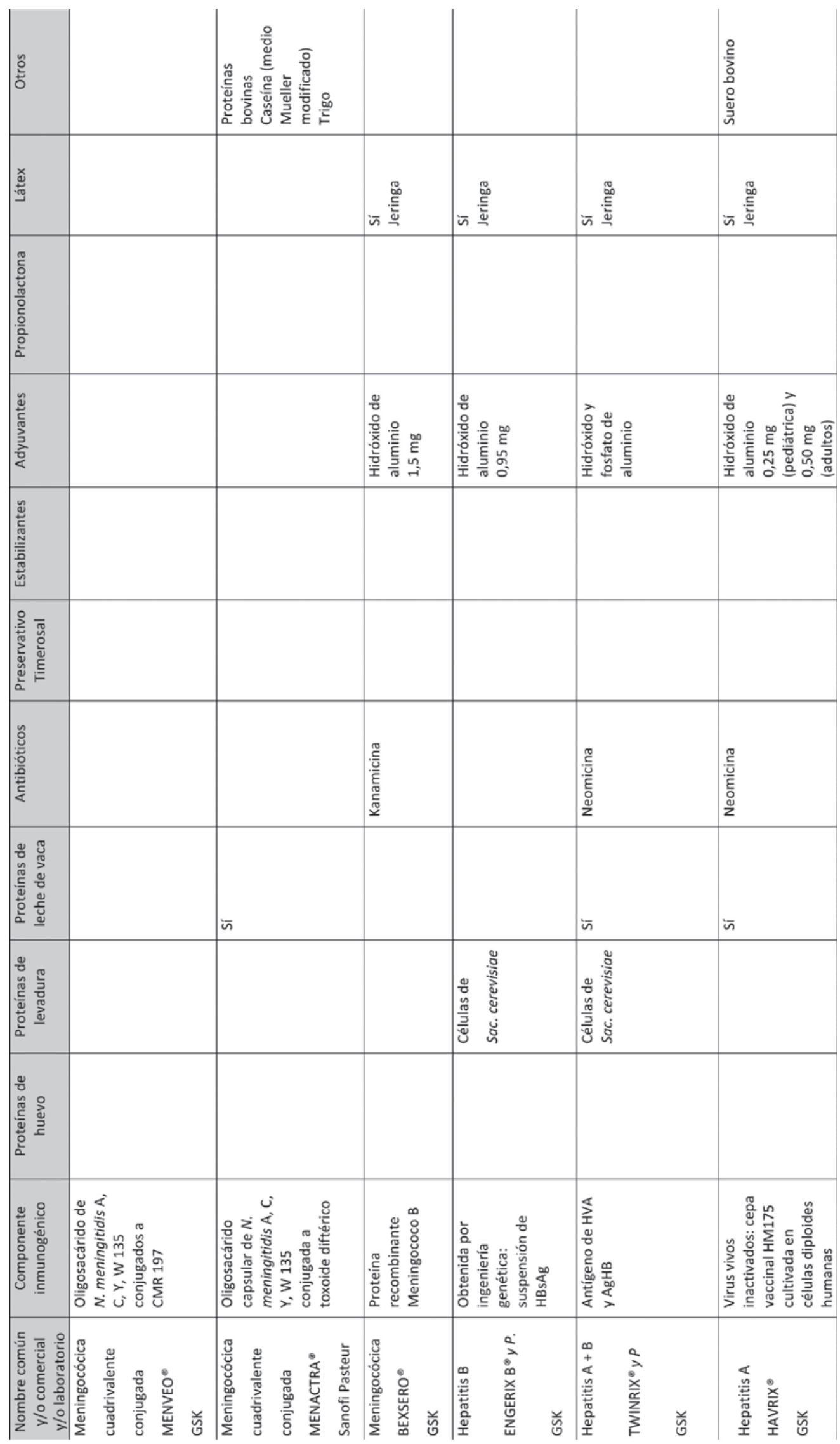




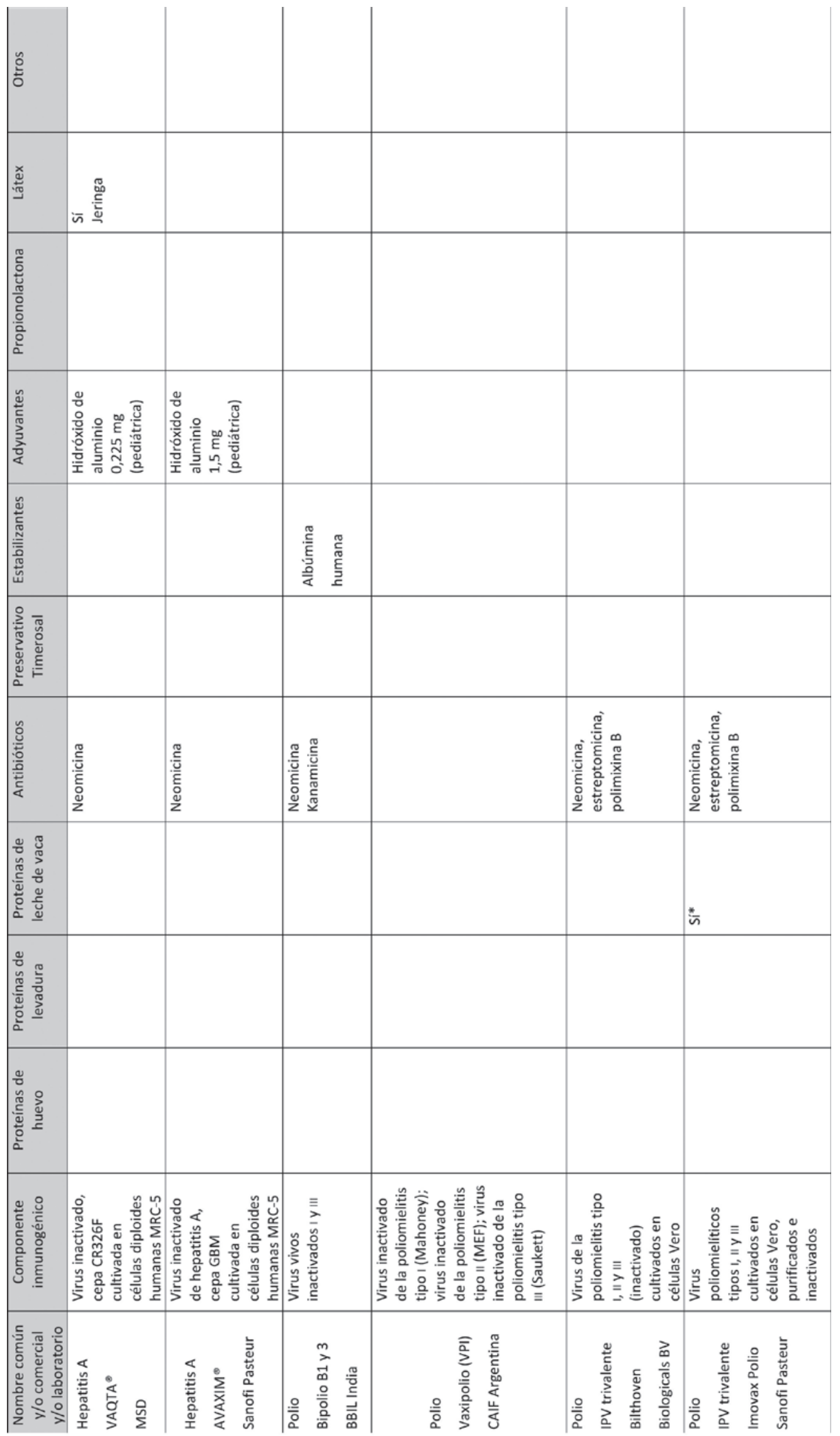




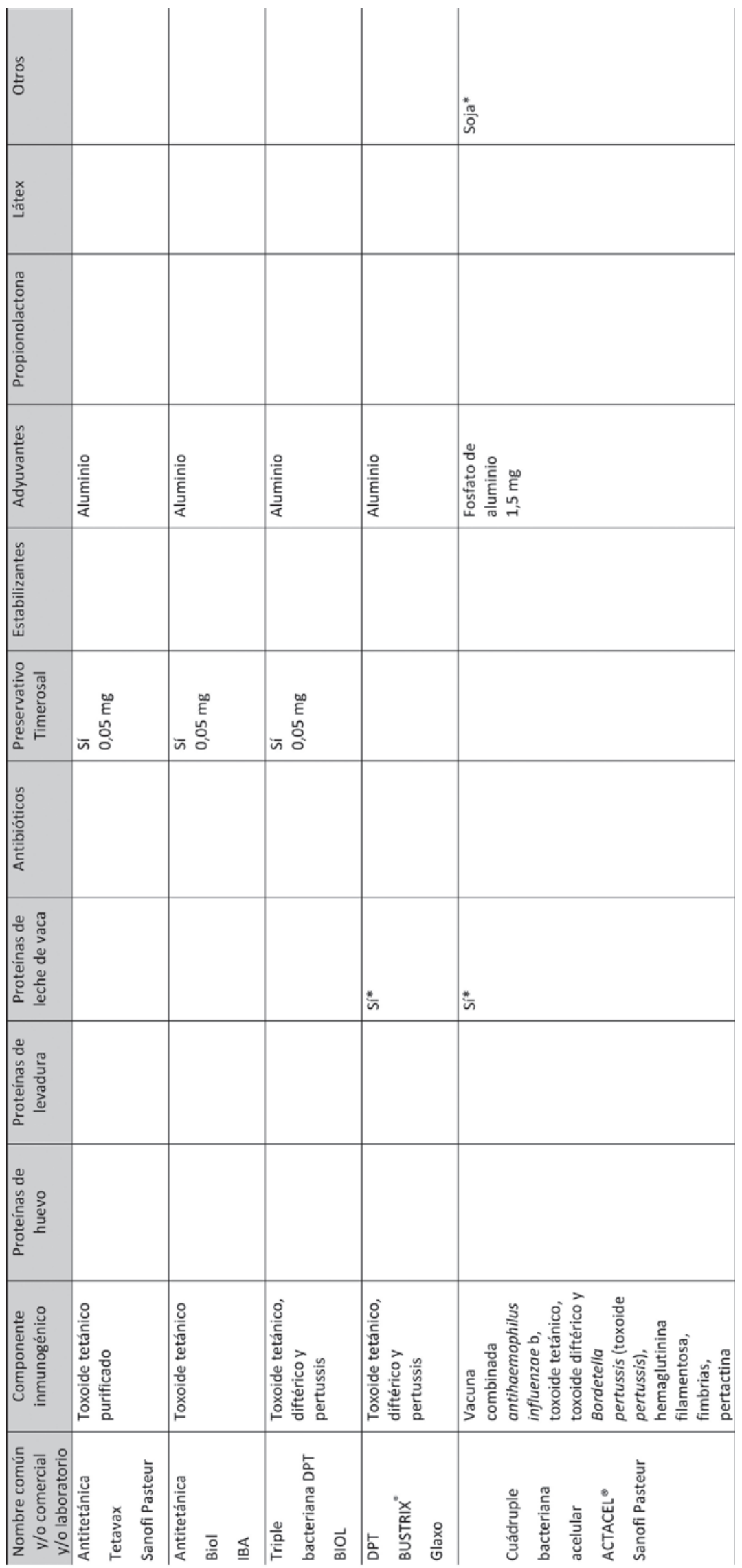




\begin{tabular}{|c|c|c|c|c|}
\hline ڤ̊ํํ & & 䓵 & 苟 & \\
\hline 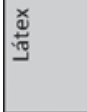 & & & 鞄 & \\
\hline 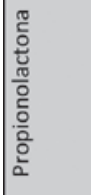 & & & & \\
\hline 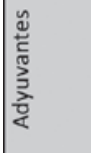 & 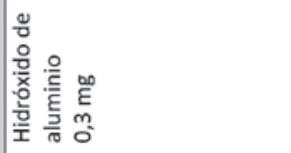 & 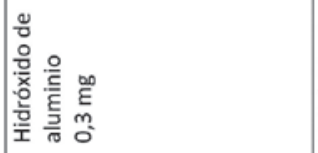 & 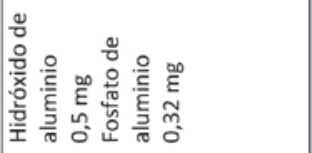 & 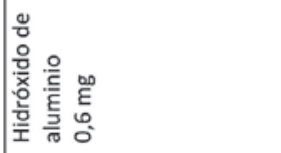 \\
\hline 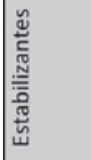 & & & & \\
\hline 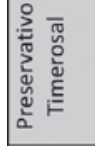 & & & & in \\
\hline 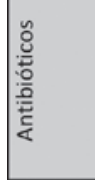 & 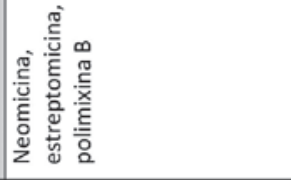 & & 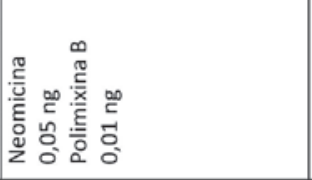 & 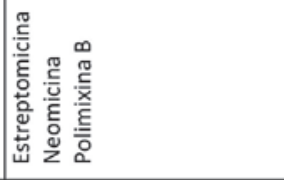 \\
\hline 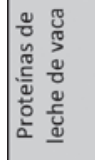 & 泫 & 泫 & 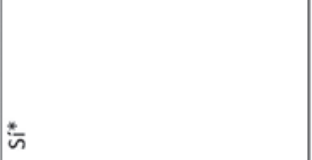 & \\
\hline 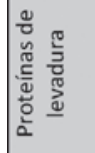 & & & & \\
\hline 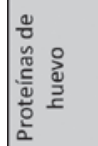 & & & & \\
\hline 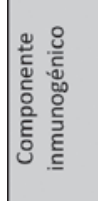 & 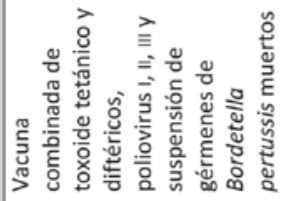 & 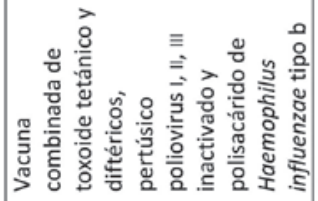 & 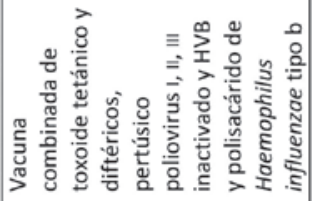 & 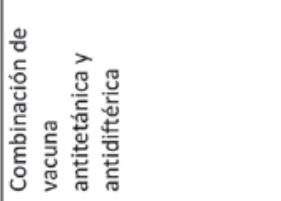 \\
\hline 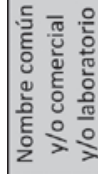 & 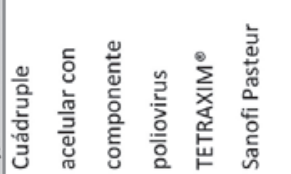 & 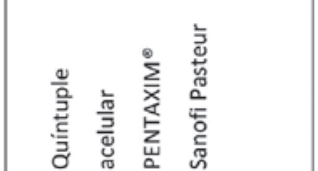 & 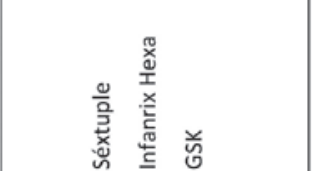 & 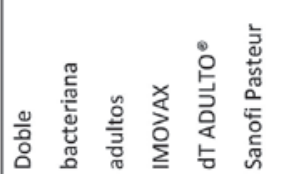 \\
\hline
\end{tabular}


S46 / Arch Argent Pediatr 2018;116 Supl 2:S34-S47 / Subcomisiones, Comités y Grupos de Trabajo

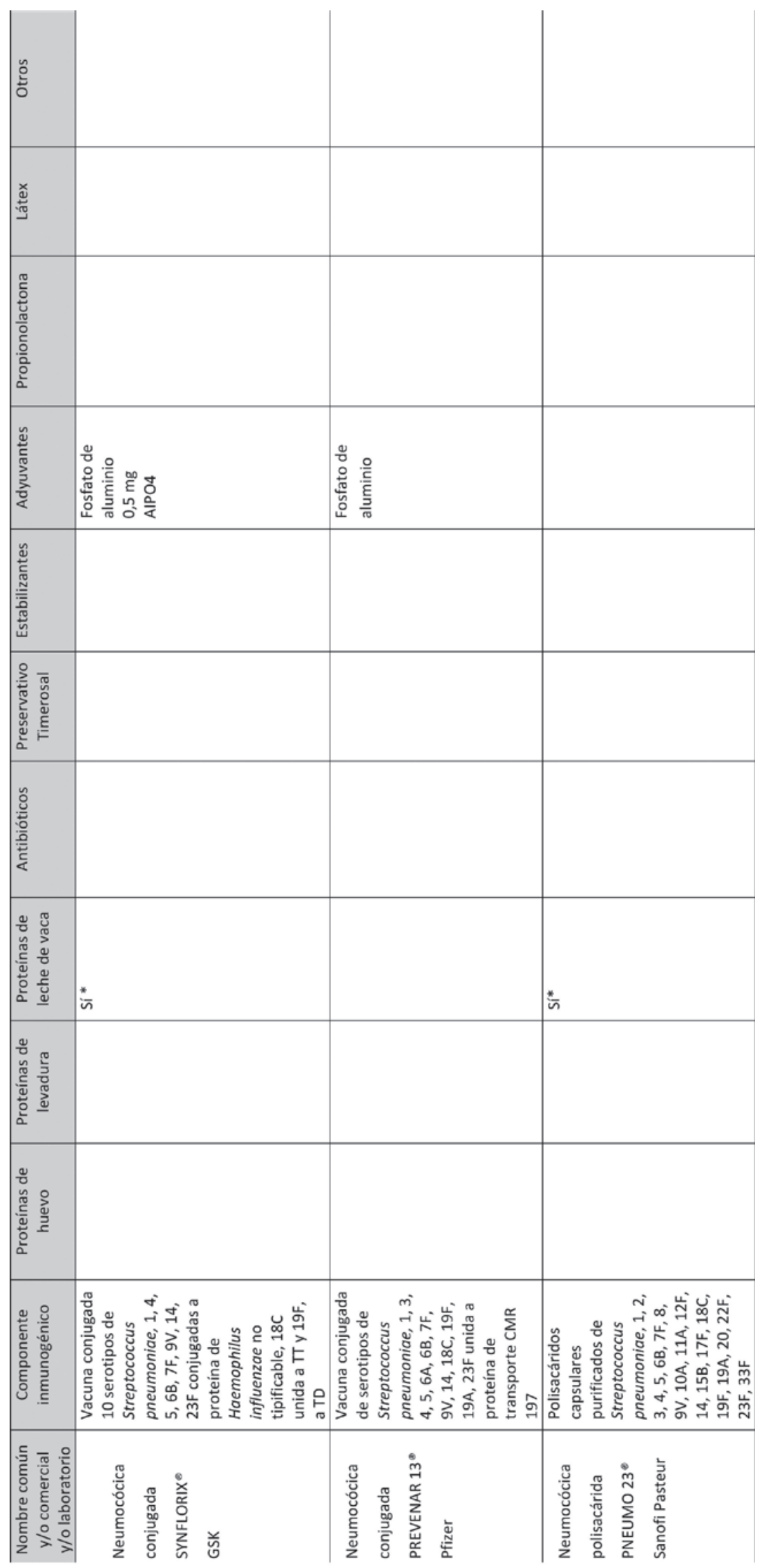




\begin{tabular}{|c|c|c|c|c|}
\hline o̊ & & & & 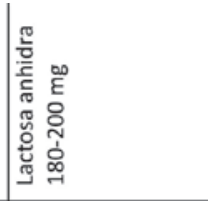 \\
\hline ج্. & & & & \\
\hline 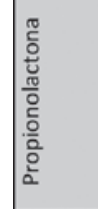 & & & & \\
\hline 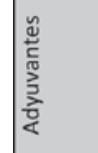 & & & & \\
\hline 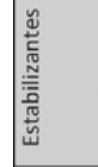 & & 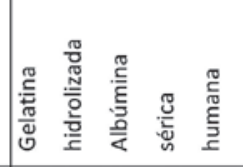 & & 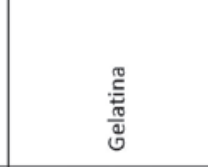 \\
\hline 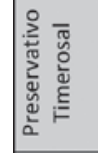 & & & & \\
\hline 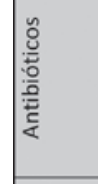 & & 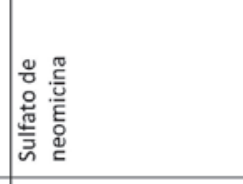 & & \\
\hline 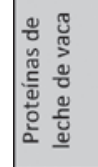 & & & & 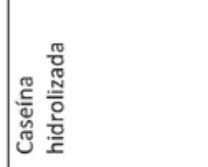 \\
\hline 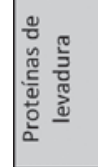 & & & & \\
\hline 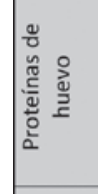 & & & & \\
\hline 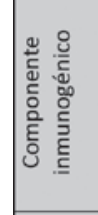 & 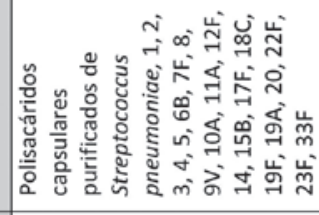 & 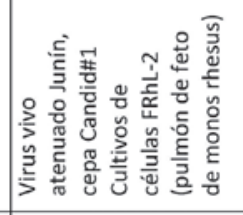 & 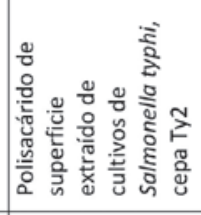 & 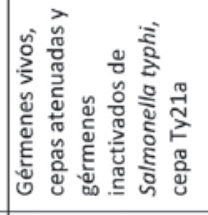 \\
\hline 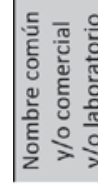 & 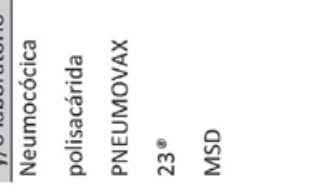 & 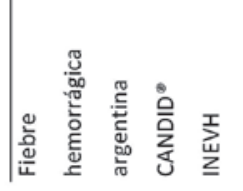 & 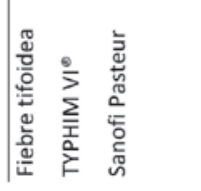 & 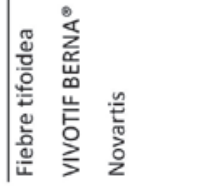 \\
\hline
\end{tabular}

